\title{
Liderazgo burocrático
}

\author{
M amani Ferrer, Héctor ${ }^{1}$; Chugden Terrones, U rías²; Tintaya Condori, Inés ${ }^{3}$; \\ Sánchez M antilla, A na; Salazar López, Julissa ${ }^{5}$
}

1,2,3,4,5 Universidad Peruana Unión (UPeU), Perú

Recibido el 28 de agosto de 2014 - A ceptado el 28 de octubre de 2014

\begin{abstract}
Resumen
Los estudios sobre el liderazgo, debido al gran interés que ha despertado, han diseminado diversas definiciones. Entre tales resalta necesariamente la conceptualización del liderazgo como una influencia integral para con sus liderados. Influencia que varía según sean las cualidades que posea el líder, lo que a su vez, definen los diferentes tipos de liderazgo. Por otro lado, la burocracia concebida idealmente como la forma racional de organización, es para el ámbito real, una de las formas más ineficaces y rígidas de dirección, este cambio se da por omisiones de variables en el marco teórico. Estos conceptos anteriores, al fusionarse, dan lugar al liderazgo burocrático, que se concibe como la capacidad de influir y dirigir por medio del poder legitimizado proveniente de las reglas. Tal liderazgo repercute en las organizaciones de manera relativamente negativa puesto que son las disfunciones las que se presentan en mayor parte, esto puede visualizarse claramente tanto en la administración como en la educación.
\end{abstract}

Palabras claves: Liderazgo, burocracia, liderazgo burocrático.

\begin{abstract}
Studies on leadership, by the great interest raised, have spread various definitions. Between those highlights necessarily the conceptualization of leadership as an integral influence with their subordinates. This Influence varies depending on the qualities possessed by the leader, which defines the different types of leadership. On the other hand, the bureaucracy, ideally conceived as the rational form of organization, it's to the actual context the most inefficient and rigid form of direction. This is taken for omissions of variables in the theoretical framework. B ureaucratic leadership is born when these concepts fuse themselves. This leadership affects on organizations relatively negative because dysfunctions are presented in the most part, this can be clearly displayed both in the administration and in education.
\end{abstract}

K eywords: L eadership, bureaucracy, bureaucratic leadership

\section{Introducción}

Desde sus inicios, tanto la burocracia como el liderazgo han sido temas que han propiciado gran variedad de debates entre los estudiosos. No solo porque se prestan para ambigüedades, sino porque tienen un impacto fundamental en la vida de las personas, y por ende, en las organizaciones. El liderazgo, por su lado, ha demostrado ser a través de toda la historia de la humanidad, el elemento fundamental para la realización de grandes proezas y significativos cambios que han guiado el transcurso de la vida humana y que hoy lo sigue haciendo. Es por tal motivo que se realizaron extensos estudios sobre este elemento, en tales se identificó muchos tipos de liderazgo que hasta hoy se siguen diversificando. Por otro lado, la burocracia, que nació como una solución para la ineficiencia de los sistemas de gobiernos clásicos y medievales, se diseminó en casi todas las grandes y complejas organizaciones. En tal contexto aparece el liderazgo burocrático como una idea weberiana de dominación racional, la que no queda expresamente concretizada y que la literatura actual no llega a profundizarla debidamente.

Es así que se establece el propósito de este trabajo, que se orienta a la búsqueda de una definición de este tipo de liderazgo, partiendo desde el análisis, por separado, de los elementos antes mencionados para fusionarlos de modo que se genere una idea concreta.

El primer capítulo hace mención a los estudios generales del liderazgo y el líder; conceptualiza tanto 
al liderazgo como al líder y presenta las cualidades principales que este último reúne.

El segundo capítulo explora a fondo el campo de la burocracia. Primero comienza mencionando los aspectos generales, que abarca el origen del término y la concepción actual de tal. Luego desarrolla el modelo propuesto por Weber sobre la burocracia, anteponiendo los términos utilizados por este, su definición en base a características y las ventajas y disfunciones que este modelo acarrea en las organizaciones. Finaliza haciendo mención al desarrollo de nuevos modelos burocráticos.

El último capítulo aborda el desenvolvimiento de la burocracia y su liderazgo en las organizaciones, tal desenvolvimiento es analizado desde la administración pública y la educación.

El presente trabajo es una compilación de datos obtenidos a través de una labor en conjunto para llegar a ofrecer al lector un texto de referencia, sin pretender que sea un completo y exhaustivo análisis del tema propuesto, sin embargo se espera que pueda servir para posteriores estudios de mayor profundidad.

\section{EI liderazgo}

\section{Concepto}

El liderazgo es un tema controversial de interés. El devenir del mismo ha despertado la curiosidad de muchos personajes doctos (Daft, 2006). A mediados de siglo $X X$, esta preocupación se incrementó orientándose a la conceptualización y constitución de su desarrollo; actualmente es objeto de polarizadas reflexiones teóricas (Ibañez, 2004), tanto para las organizaciones como para la psicología social, psicología del trabajo y ciencias afines; que tuvo sus incipientes aplicaciones con la iniciativa de Kurt Lewin quien junto a sus colaboradores trabajaron sistemáticamente el liderazgo en la empresa desde 1940 (Palomo, 2010).

$\checkmark$ arios estudios demostraron que hay más de 350 definiciones sobre liderazgo (Daft, 2006), de las cuales se tomará al liderazgo como un proceso, influencia y dirección. El liderazgo ejerce una influencia de persona a persona entre el líder y sus seguidores con el fin de lograr un futuro compartido (D aft, 2006). Esta influencia, mencionan Y ukl y V an Fleet (1992), está orientada a los objetivos de tarea y estrategias, a la identificación del grupo y a la cultura organizacional (Álvarez, 2009), además es relativamente elevada y se da en una situación específica (Pérez G. , 2012) dado que la persona que lo ejerce no lo puede hacer en cualquier contexto social o coyuntura, puesto que el liderazgo involucra un colectividad determinada y es en sí el producto de la relación entre tal colectividad y el líder (Huaylupo, 2007), ya que su naturaleza, sus complicaciones y su razón de ser se enfocan íntegramente en el grupo donde actúa (Ibañez, 2004). Este criterio de influencia se "complementa con la motivación, para ir más allá de la obediencia mecánica e incidir positivamente en la estructura organizativa y en el buen clima organizacional, que proporcione el logro de las metas institucionales" (Pérez G. , 2012), para poder liberar el máximo potencial de las personas, de modo que todos los participantes se realicen personalmente (Estrada, 2006). Por otro lado, esta influencia, aclaran Y ukl y Van Fleet (1992), está incluida dentro de la concepción del liderazgo como proceso (Álvarez, 2009). A demás, el Diccionario de la Lengua Española lo define como la dirección, jefatura o conducción de una colectividad (Estrada, 2006).

\section{EI líder}

Se sobreentiende que el líder es aquella persona que ejerce el liderazgo, por ende, la definición de tal término se desprende del concepto anterior, a esta se suma las cualidades que el líder reúne, de las cuales derivan los diferentes tipos de líder que coinciden también con los tipos de liderazgo.

\section{Definición}

El líder puede ser definido en base a sus características tales como: guía, motivador y agente de cambio. Según M urillo (2006), el líder es el que dirige, establece los objetivos, da las instrucciones, establece qué, cuándo, dónde y cómo, explica sus objetivos e intenta convencer a los sujetos para que las acepten y se involucren en la tarea. A demás este tiene la capacidad de inspirar y guiar a los demás, volviéndose un modelo de ejemplo a seguir por 
muchos otros (Estrada, 2007). También Elorriaga (1976), citado por Fernández S. (2004), plantea lo siguiente respecto al líder como guía:

El líder no es sino una persona dotada para incitar y dirigir a los demás hacia el logro de objetivos comunes, obteniendo la cooperación, respeto y confianza precisos. Su misión es lograr una presentación armoniosa de las aspiraciones colectivas, no sustituyendo las voces plurales, sino orquestándolas, como un director que no toca cada instrumento musical, sino guía y matiza aportaciones plurales. Su estatura de líder no se la da su propio deseo de mando, sino su capacidad para atraerse partidarios y para proyectar programas sugestivos para amplios sectores.

Por otro lado, Murillo (2006) explica que el líder traslada bastante responsabilidad a los seguidores, los alienta a tomar decisiones y facilita su colaboración y compromiso. A simismo hace sentir, a su gente, el orgullo y la satisfacción de su trabajo, inspira a sus seguidores a altos niveles de realización, mostrándoles cómo contribuye su trabajo a la realización de metas nobles; es un estímulo emocional en algunas de las fundamentales necesidades humanas: Ia necesidad de ser (Cornejo, 2007). El líder se convierte en un agente de cambio, puesto que, según Cornejo (2007), el líder es aquel que compromete a su gente con la acción, que convierte a seguidores en líderes y que puede otorgar a otros líderes la capacidad de ser agentes de cambio.

\section{Cualidades generales del líder}

Complementando lo anterior, cada líder debe reunir ciertas cualidades para desempeñar adecuadamente su rol, entre ellas las más importantes son: responsabilidad, benevolencia, disciplina, sabiduría y servicio. La primera cualidad puede ser entendida como la capacidad para establecer compromisos y responder de manera positiva o proactiva (Estrada, 2007), asimismo esta es necesaria para alcanzar un liderazgo eficaz (Álves, 2000). Por benevolencia, Sun Tsu expresa que cada líder debe tratar a cada trabajador con consideración, reconociendo lo que vale (Fernández J., 2002). A simismo, es la inclinación del ánimo hacia el corazón antes que a la utilidad y el interés (Estrada, 2007), teniendo un sólida noción de justicia, que es dar a cada uno lo que le corresponde (Dianine, 2010). Esto se complementa con la disciplina que es cumplir las normas y hacer que los demás las cumplan (Fernández J. , 2002), también puede aludir a un dominio propio, es decir, controlar el espíritu y orientarlo hacia el objetivo (Dianine, 2010). Por otro lado, el líder debe tener la sabiduría de conocer el momento y anticiparse a las consecuencias de sus actos (Fernández J. , 2002), además debe servir a los demás sin esperar nada a cambio (Estrada, 2007), superando el ego y volviéndolo un hábito (Dianine, 2010).

\section{Tipos delíder}

Si se estudia al líder desde el punto de vista de su comportamiento y del tipo de influencia que ejerce en sus liderados, se puede clasificar en cinco tipos: liberal, autócrata, demócrata, carismático, y burócrata.

\section{Líder liberal}

Este tipo de líder no asume la dirección y delega el trabajo a sus liderados. Según Pérez (2012) es también denominado laissez faire o de rienda suelta, este tipo de líder se centra en la delegación de funciones a sus seguidores, asimismo espera que ocupen responsabilidad, de esta manera confiere independencia y libertad de decisión de grupo, confiando en las capacidades de los subalternos, por tanto se toma bastante tiempo para elegir trabajadores eficaces, ya que es mínima su participación en el grupo, además este líder se limita únicamente a brindar la información que se requiere (García, 2002).

\section{Líder autóarata}

Este líder impone sus ideas sin tomar en cuentas las demás opiniones. Pérez (2012) señala a este tipo de líder como arbitrario e impositivo, puesto que impone métodos, opiniones y decisiones, originando insatisfacción en los subalternos. Este autor cita también a Munch (2010) quien adiciona que este líder no es participativo ni consultivo, sino quien ordena y espera obediencia, además García (2002) menciona que, como resultado, las tareas son realizadas de manera deficiente $y$, por la falta de 
motivación de grupo, se genera una constante tensión.

\section{Líder demócrata}

Este es el antitipo del líder anterior, otorga mucha importancia a sus liderados. Según Ilce (1988), citado por Pérez (2012), el líder y el equipo actúan como una unidad social descentralizando la autoridad solo en el líder.S Asimismo Herrera (2000), citado por Pérez, añade que el poder está en el equipo y no en la persona.

\section{Líder carismático}

Este líder obtiene autoridad a través de sus cualidades. Los seguidores piensan que su líder posee un regalo de inspiracion divina es por eso que no solo lo respetan y confían, sino que también lo ven como un héroe, con el que se identifican, esto le da poder al líder. Por lo tanto el centro de atención es el individuo (Álvarez, 2009). A simismo este líder es capaz de transformar al personal para lograr los objetivos de la organización, dejando del lado sus propios intereses, sin embargo tiene dificultades para interactuar con personas muy motivadas para el logro de objetivos de la misma (Pérez G., 2012).

\section{Líder burócrata}

Este líder es centrado en las reglas más que en los individuos 0 resultados. En lo que respecta a este tipo de líder, Pérez (2012) acuña que aquel ejerce su liderazgo desde su departamento de trabajo, siendo imprescindible desarrollar la estructura y los procesos de la organización, además es desconsiderado con sus subalternos, dejando de lado sus opiniones $y$, ubicando por arriba las opiniones de los superiores, de manera que su experiencia y capacidad está por encima de los demás, causando inconvenientes en la toma de decisiones por tomar en cuenta solo su manera de pensar.

\section{Aspectos generales de la burocradia}

Este modelo planteado por W eber tiene tres fuertes puntos de vista: la definición general actual, el contraste con la propuesta de W eber y la perspectiva de los estudiosos. Estos serán expuestos de manera implícita. Para entender tales aspectos, es necesario comenzar analizando los factores externos.

\section{Origen}

La palabra burocracia se refiere, etimológicamente, al poder de los funcionarios. Esta proviene del latín burrus, que dio origen a la palabra francesa bure -un tipo de tela puesto en las oficinas de cierta importancia- la cual derivó a la palabra bureau que se utilizaba primero para definir los escritorios cubiertos con dichas telas y posteriormente para designar a toda la oficina (Vélez, 2007). A unque para $V$ on Sprecher (2005) esto puede también definirse como el escritorio detrás del cual se sienta el funcionario, añade que esto al fusionarse con el vocablo griego kratos -que significa poder 0 gobierno- da a entender el poder de una oficina o de los funcionarios (Torres, 2002).

Por otro lado, el origen del término burocracia es ambigüo, y particularmente se le atribuye a dos personajes: por historia a V incent de Gourmay y por estudio a M ax W eber. La primera es sustentada por Giogloli (1981), citado por Baca et al. (2000), refiriendo que este término fue acuñado en el siglo XVIII por Vincent, para referirse al poder de los funcionarios responsables de realizar las tareas especializadas de la administración estatal de ese entonces. Acorde a 10 anterior $V$ an Creveld, manifiesta que aquel $V$ incent, era un filósofo especializado en economía y administración y planteó que tal término sea utilizado para describir cómo el gobierno había pasado de manos del Estado hacia la burocracia, bajo una nueva forma de gobernar diferente a lo propuesto por A ristóteles con la monarquía, la aristocracia y la democracia, en tal gobierno los funcionarios y militares se sentían como un cuerpo invisible que regía al estado (Patiño, 2005). A simismo Heady (2000) afirma que, según $M$ orstein $M$ arx, este término tiene un origen galo, utilizado por primera vez por un ministro de comercio francés del siglo XV III, el cual se refería al gobierno en ejercicio. En el otro sentido, los estudios académicos, atribuyen la autoría a W eber, sociólogo alemán cuyos estudios habían obtenido una trascendencia amplia, siendo objeto de un sin número de comentarios y estudios posteriores (Heady, 2000). Los estudios del sociólogo se orientaron al surgimiento de la burocracia como forma de dominación social en la antigua M esopotamia, en China, India, en el antiguo Egipto, 
en Rusia y en el Imperio Inca (Sánchez, 2001), fueron recién analizados en la década de 1940, cuando este ya había fallecido (Chiavenato, 1989). Weber derivó el término del alemán büro que significa oficina, para señalar a una organización que opera en base a fundamentos racionales (Vélez, 2007).

\section{Una definición actual}

En el pensamiento de la gente común, la definición de burocracia se concibe mayormente en base a sus disfunciones. En primera instancia, la burocracia se ve como un sistema de administración corrupto, ineficiente y abultado, paradójicamente, también se relaciona con los trabajos administrativos de países adelantados (Torres, 2002). A corde a esto Chiavenato (1989) añade que esta, en lo popular, es conocida como el papeleo que impide aplicar soluciones rápidas, es utilizado además para describir el apego de los funcionarios a las normas y la eficiencia de la organización. También se suma Sánchez (2001), señalando que algunos detractores de la burocracia la ven como un mal necesario y como un término despectivo y peyorativo, la conciben como una patología administrativa; a su vez cita a Laski quien sostenía que el poder otorgado por la burocracia a los funcionarios ponía en peligro la libertad de los ciudadanos ordinales, además, este poder se caracterizaba por la rigidez del reglamento, la inflexibilidad, la rutina, la demora de decisiones y la resistencia a nuevas experiencias.

Por otro lado, gran parte de estudiosos mantienen una posición neutral. A sí, Heady (2000) expresa que los representantes de las ciencias sociales mencionan que la burocracia está destinada a analizar un fenómeno relacionado con las organizaciones complejas de gran escala, sin darle alguna connotación positiva o negativa. A simismo, L udwing V on M oisés, citado por Patiño (2005), señala que la burocracia no puede ser califica como buena o mal, puesto que tiene una naturaleza pública. $\mathrm{A}$ esto se suma Ramírez (2007) quien opina que la burocracia es una forma de organización humana que se basa en la racionalidad, en la adecuación más conveniente entre los medios y los objetivos pretendidos, con el fin de garantizar la máxima eficiencia posible, en las organizaciones.
Por el contrario, a favor de una posición positiva, Cervantes \& Corrales (1987) explican que la burocracia u organización es el sistema en el que la división del trabajo es sistemática y correctamente realizada, teniendo en cuenta los fines propuestos. A demás los mismos autores citan a $\mathrm{K}$ art quien define que la burocracia es el tipo de cooperación en el cual las funciones de cada parte del grupo han sido previamente ordenadas y establecidas, de esa manera existe la garantía de que las actividades planeadas serán ejecutadas sin mayores tropiezos. A corde a lo anterior, A rico \& Tula (2005) mencionan que, lejos de una visión pesimista, si se toma como punto de referencia la conceptualización de W eber, se puede considerar a la burocracia como una variante moderna y específica de las soluciones, dadas al problema general de la administración. Sin embargo Zabludovsky (2007) al no compartir menciona que:

Si bien es cierto, durante la primera "modernidad" que todavía caracterizó a una parte del siglo XX - se vieron cumplidos los pronósticos de $M a x$ Weber sobre la importancia de la burocracia, en estos días (modernidad tardía), la realidad es eminentemente distinta. Las grandes estructuras piramidales del sector público y privado tienden a desvanecerse. $L$ as concepciones de lealtad al cargo y autoridad imperativa que constituyen el sustento de la jerarquía burocrática ya no parecen operar en el mundo actual $y$, en su lugar, tenemos una gama cada vez más amplia de modelos ocupacionales y una creciente importancia de las relaciones horizontales y de intercambio que no se ajustan a las nociones tradicionales de una jornada de trabajo atendida a un horario determinado.

\section{M odelo burocrático de Weber}

Dentro del pensamiento weberiano hay dos factores influyentes: la autoridad y la racionalidad. En base a esto se desarrollan todos sus planteamientos y se disgregan las definiciones, características y consecuencias. Tales constructos serán descritos secuencialmente en el desarrollo de los siguientes apartados.

\section{Poder, legitimación y autoridad}

En su estudio, Weber introdujo y definió al poder como la obediencia a las órdenes, a la legitimidad 
como justificación y a la autoridad como un poder justificado. Con respecto al primer término, Hermida y Sierra (1989) expresan que es la capacidad de inducir a otro a aceptar órdenes, en otras palabras, según Torres (2002), es la capacidad que tiene $A$ para hacer que $B$ haga lo que $A$ quiere, incluso, aunque $B$ no lo quiera. Esta forma de conceptualizar alude a la legitimación, que es el nivel de aceptación de las órdenes de parte de un subordinado porque comparte 0 está de acuerdo con el sistema de valores del superior que se le ha impartido (Hermida \& Serra, 1989); y de la combinación de estos dos conceptos nace la autoridad: un poder legítimo (Torres, 2002). En base a esta autoridad, W eber hace un análisis orientado al liderazgo y lo clasifica en tres tipos:

\section{Autoridad tradicional}

Esta autoridad justifica la dominación con la costumbre. Para Hermida y Sierra (1989) es un sistema de autoridad donde la aceptación de los súbditos se verifica por tradición, por influencia de las subculturas; las órdenes se aceptan por considerarse justificadas en la tradición; siempre han sido así y así deben ser. Lo que en Chiavenato (1989) se convierte algo no racional y extremadamente conservador, siendo así una dominación cuya legitimación de su poder proviene de la creencia en el pasado eterno, la justicia y en la forma tradicional de actuar. A corde con lo anterior, Daft (2007) añade que esta autoridad confía en las tradiciones y en la legitimidad del estatus de la gente que ejerce su autoridad a través de esas costumbres. Esto se puede apreciar tanto en el derecho divino de los reyes o la influencia mágica de los hechiceros tribales (Hellriegel, Jackson, \& Slocum, 2006), como también en el dominio patriarcal del padre de la familia y el poder del jefe del clan (Chiavenato, 1989).

\section{Autoridad carismática}

Esta autoridad tiene como fundamento de su poder a la influencia proveniente del líder. Chiavenato (1989) explica que se da cuando los subordinados aceptan como justificadas las órdenes del superior, por causa de la influencia de la personalidad y del liderazgo superior con el cual se identifican. Es esa influencia, comenta Daft (2007), la que se convierte en la base de esta autoridad, ya que los seguidores sienten devoción por el carácter ejemplar o heroísmo y por el orden que imparte aquel poseedor de este poder. Esto es lo que caracteriza a las organizaciones militares revolucionarias. A manera de ejemplo están las sociedades de los periodos revolucionarios: Rusia, desde 1917 y A lemania, desde 1933 (Torres, 2002).

\section{Autoridad racional-legal}

Esta autoridad se considera la más adecuada ya que posee su legitimación en un sistema de reglas y procedimientos racionales. Los súbditos aceptan las órdenes (reglamento) porque están de acuerdo con reglas más abstractas, que consideran legítimas, de las cuales se deriva el reglamento, teniendo como claro ejemplo de esta autoridad a la democracia moderna (Torres, 2002). De la misma forma, Chiavenato (1989) añade que este es el tipo de autoridad técnica, meritocrática y administrada, que se basa en la promulgación, la idea básica tiene su fundamento en el hecho de que las leyes pueden ser promulgadas y reglamentadas libremente por procedimientos formales y correctos. Esto es recalcado por Blanco (1994), mencionando que este tipo de autoridad (dominación) se sustenta en la creencia de la legalidad de ciertas ordenanzas. A sí pues es en un sistema coherente de reglas abstractas, -base de la administración, un proceso que busca la aplicación racional de los intereses especificados en el orden- que se gobierna a la organización, dentro de los límites establecidos por los preceptos legales y guiados por principios que gobiernan al grupo (Restrepo, 2011).

\section{La burocracia ideal de Weber}

El modelo que impulsó Weber se eximía de un marco mayormente teórico cuya definición ideal, basada en la racionalidad, se mostraría en la práctica con ventajas contadas $y$, por otro lado, con una fuerte expansión de las disfunciones.

\section{Definición de Weber}

La burocracia de Weber entra en contraste con el pensamiento actual, es percibida como una forma racional de autoridad. Recalcando tal pensamiento Marín (2006) cita el enunciado de Dávila (2001) quien dice que en la actualidad la burocracia es referida indebida y peyorativamente a aquellos organismos ineficientes que escasamente operan, obstruidos por medio del papeleo y el desgano de los 
empleados. Esto es contrario al propósito de la burocracia de Weber, que intentaba introducir un sistema racional como un modelo puro de dominación, el cual consistía en una forma de dominación basada en la administración de cualquier tipo de recursos (V ásquez, 2006), convirtiéndose así en el sistema más racional de ejercer tal dominación (Santa Cruz, 1997) y "un instrumento eficiente de poder" (Faria \& M eneghetti, 2011). Todo esto con el fin de establecer la estructura, la estabilidad y el orden de las organizaciones, siendo flexibles, con el propósito de ser el medio más eficiente de trabajo (Cervantes \& Corrales, 1987).

No obstante, W eber no llega a definir la burocracia, sino que expone las características como definición, entre estas resaltan: la división del trabajo, la meritocracia, la normatividad, la impersonalidad y la jerarquía. Esto puede variar según el punto de vista de los autores. En primer lugar, la división del trabajo, tal como lo menciona Restrepo (2011) es la especialización de tareas por medio de la distribución de obligaciones $u$ oficios y roles entre un cierto número de puestos, dentro de una estructura jerarquizada; la utilización de la normatividad como elemento de la regulación del proceso de decisión; la estandarización de los procedimientos y la centralización de la autoridad, además es según $\mathrm{Da}$ Silva (2002), la desmembración de las actividades en tareas simples, de modo que cualquier persona de la organización se pueda convertir en alguien especializado en un tiempo mínimo, lo cual lleva a la eficiencia organizacional, en otras palabras, la eficiencia de las organizaciones depende de que tengan un tipo de trabajador que desarrolle las funciones requeridas de una manera adecuada (V ásquez, 2006). En lo concerniente a meritocracia, exponen Cervantes \& Corrales (1987) que la selección de personal, en una organización burocrática, es en base a los méritos y la calificación por criterios racionales que determinan la competencia y capacidad técnica del individuo. Con respecto a la normatividad, es según $B$

lanco (1994), la existencia de reglas, leyes y disposiciones que describen los deberes y derechos de los funcionarios y subordinados, con esto se regula la conducta de cada cargo y se especializa al ocupante de manera que su desempeño sea racional,
Da Silva (2002) añade que en base a la existencia de estas reglas y derechos se tomarán las decisiones administrativas. Por otro lado, Cervantes y Corrales (1987) se refieren a la impersonalidad como falta de consideración a las personas, concentrando el poder en sus cargos y no en sí mismas, además es en base a estos cargos que se establece la jerarquía, definiéndose así los cargos de control y de autoridad.

\section{Ventajas}

A pesar de las existentes críticas al modelo burocrático, se le atribuyen aportes importantes como: racionalidad, precisión, seguridad, especialización y previsibilidad. Según Hellriegel et al. (2006), la racionalidad permite tomar decisiones dirigidas a lograr las metas de la organización, además M aqueda y Llaguno (1995) mencionan que este modelo otorga precisión en la definición de tareas a través de funciones y responsabilidades, generando así claridad y transparencia, de esta manera, cada uno sabe lo que debe hacer evitando el desconocimiento de funciones; además las reglas y normas ayudan a mantener seguridad interna evitando conflictos, asimismo agregan que se debe graduar la dosis de racionalidad y estandarización para que no se convierta en una desventaja. Por otro lado, Da Silva (2002) menciona la especialización como otra ventaja, que permite que las personas desarrollen sus potenciales en el área que se desempeñan en la estructura, ventaja que tiene como fin dar forma a la organización estableciendo jerarquía de mando en cada nivel y subordinados. $Y$ por último, la previsibilidad que mantiene los efectos de la experiencia válida, las reglas, normas, estructura y otros elementos de la burocracia, hacen que la organización goce de estabilidad.

\section{Disfunciones}

Así como se encuentra aportes del modelo burocrático que benefician a la organización, también existen disfunciones para la misma como: despersonalización, excesiva reglamentación, gran concentración del poder en los altos cargos y demasiado formalismo. Según M erton (1964), citado por Da Silva (2002), el modelo de Weber puede originar una mayor despersonalización de las relaciones, otorgando mayor importancia a los cargos, dejando de lado a los funcionarios. A demás 
este punto de vista añade que la burocracia puede llegar a convertirse en un fin para sí misma, y no para quienes lo diseñaron (M aqueda, J., \& Llaguno, 1995). Otra disfunción dada, prosigue Merton (1964), citado por Da Silva (2002), es que este modelo puede ocasionar una mayor internalización de las directrices, es decir, las normas y reglas llegan a convertirse de medios a objetivos, también agrega que la jerarquía como base del proceso de decisión, ocasiona que las decisiones de los altos cargos sean tomadas, en algunos casos, por personas incapaces de asumir esta función, por último identifica al excesivo formalismo y la conformidad con las rutinas, produciendo una necesidad de documentar y formalizar todas las decisiones tomadas.

\section{Otros modelos burocráticos}

El modelo burocrático de W eber es reforzado por los subsiguientes estudios realizados a fin de superar las omisiones que presentaba. Según Torres (2002) explica que las características burocráticas fueron diseñadas tomando en cuenta que la organización operaría sin obstáculos en el logro de sus fines, sin embargo en un estudio profundo se detectan algunas omisiones, como la existencia de organizaciones informales y la inestable conducta del ser humano, tales omisiones afectan al éxito del planteamiento teórico de esta propuesta (Fig. 1).

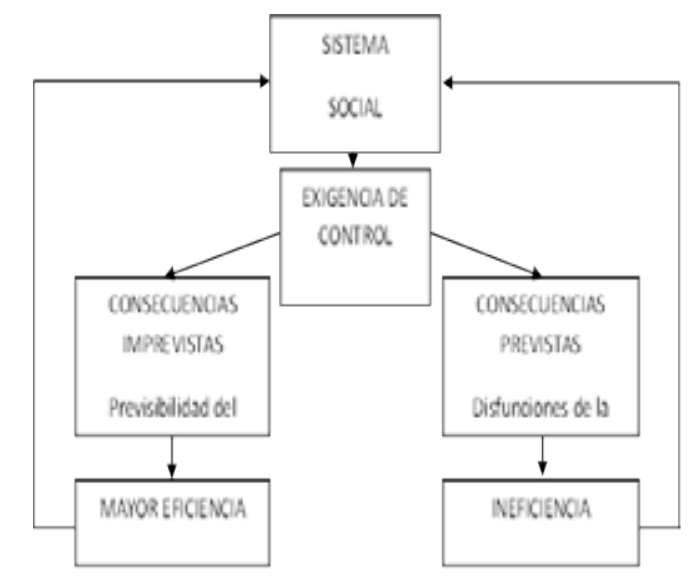

Modelo de Merton

Fig. 1. A nálisis del modelo burocrático de W eber inoperancia por la sujeción a las reglas. Según Chiavenato (1989), el modelo de Merton (Fig. 2) tiene su razón de ser en las consecuencias no previstas de organizar dentro de los principios de la máquina, tal como se describe a continuación: este proceso empieza con la necesidad de control por parte de la organización impuesta por la autoridad superior. Esta exigencia adquiere la forma de sobrevaloración en la confianza del comportamiento organizacional, es decir, previsibilidad y control del comportamiento, sin embargo las disfunciones, que anteriormente plantea $M$ erton, generan resistencia en el comportamiento de los miembros de la organización, quienes deciden a defenderse de estas presiones externas, lo que provoca la justificación de la acción individual y eleva el grado de dificultad en las relaciones con los clientes de la organización, ocasionando un trato insatisfactorio (el principal objetivo de las organizaciones). Es decir las disfunciones provocan rigidez del comportamiento, acentuando la necesidad de defensa de la acción individual y reforzando la importancia otorgada a la confianza en el comportamiento como consecuencia de las sugerencias realizadas por las partes (trabajadores y clientes). Por otra parte, Rosas, Trevera, y Rosas (2009) opinan sobre el pensamiento de M erton:

M erton no cree en las bondades de la burocracia, sino más bien la crítica en base a sus disfunciones. Resulta ser más abierto y crítico del sistema positivista: prefiere hablar de nociones de función y disfunción en los sistemas sociales, al caracterizar como función a todo aquello que facilite el equilibrio del sistema y, como disfunción, a todo aquello que facilite su desequilibrio. De esta manera, la falta de normas sería la disfunción aguda entre las normas y los objetivos culturales, por un lado, y las capacidades sociales estructuradas de los individuos del grupo relacionadas con obrar de acuerdo con aquellas pautas culturales por el otro. $M$ erton intenta representar la burocracia a través de un conjunto complejo de relaciones que se establecen, como ya se dijo, entre cierto número de variables. 


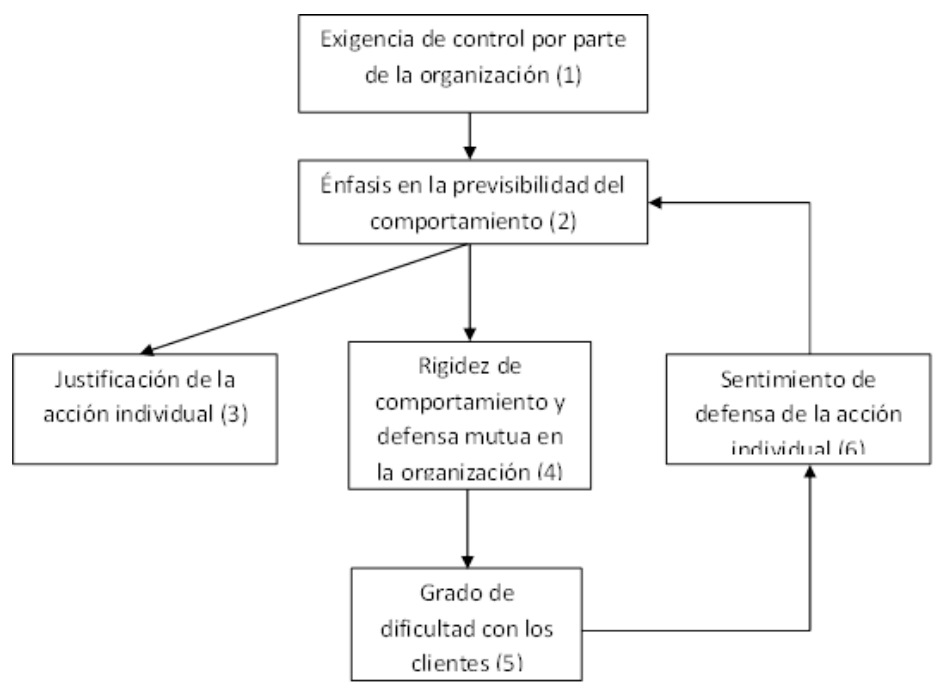

Fig. 2. El modelo burocrático de M erton

\section{EI liderazgo burocrático en las organizadiones}

\section{Rasgos generales}

El liderazgo y la burocracia al fusionarse desarrollan una influencia necesaria en las organizaciones, esta influencia afecta de varios modos, entre ellos resaltan: el ejercicio de las disfunciones en la administración y la obstaculización de la enseñanza en la educación.

\section{E I liderazgo burocrático}

El liderazgo burocrático puede conceptualizarse en base a definiciones previas de liderazgo y burocracia. Tanto Daft (2006), Ibáñez (2004), Pérez (2012), Huaylupo (2007), Álvarez (2009), Estrada (2006), además de y otros autores concuerdan que el liderazgo involucra necesariamente una gran influencia que afecta a todas las áreas de sus liderados. Por otro lado, la mayoría de estudiosos como Vásquez (2006), Cervantes y Corrales (1987), Santa Cruz (1997), M arín (2006) y otros afirman que la burocracia se visualiza como positiva en un estado plenamente idealista, en otras palabras, es solo en teoría la forma más racional de dirección. Sin embargo, según Maqueda y Llaguno (1995), Da Silva (2002) y otros suelen desenvolverse de manera rígida, reglamentaria y pesada, puesto que de estas cosas los burocráticos obtienen la autoridad necesaria para ejecutar sus planes. Por tanto, al fusionarse tales definiciones, se desprende que el liderazgo burocrático es la capacidad de influir y dirigir por medio del poder legitimizado, proveniente de las reglas.

\section{L as organizaciones burocráticas}

Las organizaciones burocráticas tienden a depersonalizar a sus miembros y mantener el poder en la cúpula de la organización. Según Beltrán (1997), el tipo de organización burocrática es opuesto a cualquier receptividad, a privilegios 0 favores individuales y a preferencias amistosas 0 familiares, exigiendo una rigurosa igualdad de trato sin acepción de personas (Batesi, 1989). La socialización va unida inevitablemente a la vida social, sin embargo la socialización que propone la organización burocrática es diametral mente diferente a la de la mayoría de las culturas, sociedades y comunidades, por cuanto se propone una despolitización efectiva tanto de los miembros como de los clientes de la organización. Por otro lado, Ramírez (2007) expone que el fundamento de la organización burocrática es monocrático y sustentado en el derecho a la propiedad privada, en donde sus dirigentes ya sean los dueños o no de la empresa, poseen un poder y un elevado status social y económico, constituyéndose en una nueva y poderosa clase social, Ilamada de los burócratas, producto del nacimiento de los modelos de sociedad de mercado.

\section{E n la administración pública}

La burocracia $y$, por ende, su liderazgo se desempeñan como reguladores, sin embargo se diferencian las disfunciones burocráticas en tales. EI modelo burocrático aplicado en la administración desde el siglo XVIII se parecía a la panacea y pretendía a quedarse por mucho tiempo en las organizaciones públicas, según lo que Weber planteaba a la burocracia, como regulador de las organizaciones mediante normas establecidas para la distribución y los propósitos que son convenientes, asentando así las bases de funcionamiento de las organizaciones burocráticas que según Ramiro (1999) y M uñoz (2007) es un sistema organizativo. La nueva administración pública se ha transformado en una referencia obligada de modernización administrativa, sin embargo la nueva globalización 
en términos económicos, políticos y sociales, han demostrado las limitaciones que han proporcionado a la administración los modelos de conducta durante los años 2008-2010 (B allesteros, 2010). No obstante uno de los problemas de la administración pública es que considera al funcionario como un segmento de un solo propósito convirtiéndolo apático y viéndose atrapado en una red provocado por la administración rígida y jerarquizada con una carga de autoritarismo y politización; asimismo es percibida como lenta engorrosa y con tendencia hacia la corrupción, con una cultura funcional, donde no existe responsabilidad de las autoridades hacia los demás (Pérez V . , 2002).

\section{En la educación}

En el campo de la educación, la burocracia y su liderazgo tienden a ser calificadas como obstáculos para la enseñanza, peligros para tal profesión e incapaces de controlar. Si bien, la concepción weberiana considera a la burocracia como una forma de organización racional que adecúa los medios y objetivos, para lograr la máxima eficiencia, concentra los medios administrativos en la cima de la jerarquía utilizando reglas racionales e impersonales (Lucero, 2002). El desempeño de tal en la educación es muy diferente, esto es argumentado por Bastiani et. al (2012) quienes resaltan, a través de su estudio, que el trabajo de los profesores es muchas veces impedido por la estructura burocrática, de esa manera no logran un trabajo pedagógico de largo aliento, tales profesores mencionan que las tareas administrativas obstaculizan el ejercicio de actividades curriculares 0 de planeación que aseguren un aprendizaje significativo en los niños. Por otro lado, M orgade (2007) expone que la lógica burocrática implica una organización piramidal en la que cada estamento es responsable y garante del funcionamiento de la institución, siendo así, la autoridad emana de la jerarquía burocrática y del estado educador que otorga trabajo a los profesores y establece sanciones, por tanto esto se convierte en una autoridad vertical. Por tal motivo, según (Fernández S. , 2004), los mecanismos burocráticos son un peligro para el profesionalismo y a través de estos la administración pública puede fiscalizarlo. Por otro lado, la burocracia, según M orgade (2007) tiende a calificar el trabajo y al trabajador de la educación, lo que mayormente conlleva a la descalificación de tales, y resulta casi imposible hacer un seguimiento, asesoramiento 0 diseñar proyectos.

\section{Condusión}

El liderazgo ha sido y es un tema que despierta gran interés y controversia que han generado numerosos estudios, los cuales resalta el concepto de liderazgo como influencia, proceso y dirección.

A simismo el líder se concibe como una persona motivadora, que dirige y se vuelve un agente de cambio. A quél debe reunir ciertas cualidades para ejercer su liderazgo, tales como: ser responsable, benevolente, disciplinado, sabio y servicial. En base a las cualidades se desprenden diferentes tipos, entre ellos destacan el líder liberal quien delega su responsabilidad, el líder autócrata quien es impositivo, el líder demócrata que trabaja en equipo, el líder carismático quien inspira a sus liderados y por último el líder burócrata que se centra en las leyes y el cumplimiento de tales

Por otro lado la burocracia concebida etimológicamente como el poder de los funcionarios tiene su origen en dos personajes: Vincent de Gourmay y Weber. Desde el pensamiento popular es conceptualizada en base a sus disfunciones. Con respecto a esto, muchos estudiosos tienen una posición neutral, lo visualiza como una forma de dirigir organizaciones complejas.

Para analizar la burocracia desde el punto de vista de W eber es necesario aclarar que para este, el poder es la capacidad para hacer obedecer, que si se legitimiza (justifica) se convierte en una autoridad. De tal autoridad se desprenden tres tipos: la autoridad tradicional, una dominación en base a las costumbres; la autoridad carismática, dominación a causa de la influencia del líder; y la autoridad racional legal, fundamentada en la racionalidad y las reglas.

Para W eber la burocracia es el sistema más racional de dominación, pero realmente lo define en base a sus características que son: división del trabajo, 
meritocracia, normatividad, impersonalidad y jerarquía. Este modelo de dominación ofrece las ventajas de la racionalidad, precisión, seguridad, especialización y previsibilidad. Sin embargo presenta varias disfunciones, tales como: despersonalización, excesiva reglamentación, autoridad vertical y demasiado formalismo. A nte este modelo y sus falencias se establecen otros como el modelo burocrático de $M$ erton que visualiza variables previstas y no previstas en la acción de la burocracia sobre las personas.

En base a todos estos conceptos se llega a entender que el liderazgo burocrático es la capacidad de influir en las personas por medio de las reglas. LoS efectos del ejercicio de tal liderazgo en la administración pública se reflejan en el desarrollo apático de los funcionarios y la rigidez del movimiento de tales organizaciones, en el campo de la enseñanza, obstaculiza, significa un peligro y es incapaz de controlar.

\section{Referendias}

Álvarez, J. (1984). Burocracia y poder político en el régimen franquista. España: Instituto Nacional de A dministración pública.

Álvarez, J. (2009). Estilos de liderazgo en la policía local de la comunidad Valenciana. Valencia: Universidad de V alencia.

Álves, J. (2000). Liderazgo y clima organizacional. Revista de Psicología del Deporte, IX (1-2), 123133.

Arico, J., \& Tula, J. (2005). Diccionario de política (Catorceava ed.). M éxico: Siglo X XI Editores.

Baca, L., B okser, J., Castañeda, F., Cisneros, H., \& Pérez, G. (2000). Léxico de la Política. México: FLACSO M éxico Publicaciones.

Ballesteros, V. (Diciembre de 2010). Importancia de la organización en los procesos de la gestión pública. IA PE M (77), 245-247.

Bastiani, J., Ruiz, L., Estrada, E., Cruz, T., \& A paricio, J. (2012). Perfiles Educativos. Política Indígena Educativa, 34(135), 8-25.

B atesi, R. (1989). Práctica crítica de la administración educativa. España: U niversidad de $V$ alencia.
Beltrán, M. (1997). La formación y los empleados públicos. (u. a. madrid, Ed.) REIS, 51-68.

Blanco, M. (Setiembre de 1994). Hacia una antropologìa de la burocracia. Nueva A ntropología, XIV (046), 117-129.

Cervantes, O., \& Corrales, G. (1987). Administración en instituciones públicas: antología (V ol. I). San José: Universidad estatal a distancia.

Chiavenato, I. (1989). Introducción a la teoría general de la administración. Santa Fe, M éxico: M cGraw-Hill.

Cornejo, M. (A gosto de 2007). Liderazgo de excelencia. Veritas, 51(1632), 48.

Da Silva, R. (2002). Teoría de la Administración. $M$ éxico: Thomson.

Daft, R. (2006). La experiencia del liderazgo (Tercera ed.). M éxico: Thomson.

Daft, R. (2007). Teoría y diseño organizacional (N ovena ed.). Santa Fe, M éxico: Cengage L earning Editores.

Dianine, A. (2010). Perfil del líder: hacia un liderazgo virtuoso. España: Editorial formatic M y C. 
Estrada, S. (diciembre de 2006). Modelos de liderazgo en organizaciones cambiantes. Scientia Et Technica, XII(032), 295-300.

Estrada, S. (mayo de 2007). Liderazgo a través de la historia. Scientia Et Technica, X III(034), 343-348.

Faria, J., \& Meneghetti, F. (2011). Burocracia como organização, poder e controle. (portuguese). Revista de A dministração de Empresas, LI (5), 424439.

Fernández, J. (2002). Liderazgo empresarial en tiempos de cambio, según Sun Tsu. Harvard Deusto Business Review, XXIII(109), 64-71.

Fernández, S. (Julio de 2004). Sobre el concepto y el estudio del liderazgo político. Psicología Política, 15(29), 7-29.

Garcia, M. (2002). Habilidades sociales del líder político. Universidad Complutense de Madrid. M adrid: Editorial de la U niversidad M adrid.

Heady, F. (2000). Administración pública: una perspectiva comparada. M éxico: Fondo de cultura económica.

Hellriegel, D., Jackson, S., \& Slocum, J. (2006). Administración: un enfoque basado en competencias. M éxico: Thomson.

Hermida, J., \& Serra, R. (1989). Administración y estrategia. Buenos Aires, Argentina: Ediciones Machi.

Huaylupo, J. (2007). El liderazgo: un poder relativo. Revista de Ciencias Sociales, I(15), 103-124.

Ibañez, E. (2004). Liderazgo y compromiso social (Primera ed.). M éxico: Universidad Autónoma de San Luis de Potosí.

Lucero, A . (junio-julio de 2002). Burocracia M unicipal y el Proyecto Educativo. Revista del Centro de Investigación. U niversidad la Salle, 5(018-017), 1728.
M aqueda, J., \& Llaguno, J. (1995). M arketing estratégico para empresas de servicios. España: Editorial Dias de Santos.

Marín, D. (Julio-Diciembre de 2006). El sujeto humano en la administración: una mirada crítica. Cuadernos de A dministración, XIX (032), 135-156.

Morgade, G. (Mayo - Agosto de 2007). Burocracia Educativa, Trabajo D ocente y $G$ enero: supervisoras que conducen "poniendo el cuerpo". Educacion y Sociedad, 28(99), 400 - 425.

M uñoz, W. (Diciembre de 2007). El servicio civil: una necesidad para una admnistración postburocrática. Revista de Economía y Administración, 69(69), 3956.

M urillo, F. (2006). Una dirección escolar para el cambio: del liderazgo transformacional al liderazgo distribuido. Revista Electrónica Iberoamericana sobre calidad, eficacia y cambio en educación, 4(4), 13-14.

Palomo, M. (2010). Liderazgo y motivación de equipos de trabajo (Sexta edición ed.). M adrid, España: ESIC Editorial.

Patiño, C. (2005). El origen del poder de Occidente: Estado, guerra y orden internacional. Madrid: Taurus.

Pérez, G. (setiembre de 2012). Gestión, liderazgo y valores en la administración de centros educativos. "Gestión de liderazgo y valores en el Centro Educativo Escuela Fiscal Mixta N 208 Ciudad de Azogues, de la ciudad de Guayaquil, durante el periodo lectivo 2011 - 2012". tesis, UTPL, Guayaquil.

Pérez, V. (octubre de 2002). La lucha contra la corrupción en Venezuela : balance y perspectiva en el marco de la nueva administración pública. VII Congreso Internacional del CLAD sobre la Reforma del Estado y de la Administración Pública. Lisboa, Portugal: U niversidad de los A ndes (V enezuela). 
Ramírez, L. (2007). Teoría Administrativa. Documento de docente, Universidad Santiago de Chile, Departamento de Gestión y Políticas Públicas.

Restrepo, M. (Enero-Junio de 2011). La administración pública en la Constitución de 1991: sincretismo involuntario entre la burocracia, el gerencialismo y la gobernanza. Revista Estudios Socio-jurídicos, XIII(001), 365-388.

Ribeiro, C. (2011). Perfil de liderazgo de los gerentes de Banco Hacer Agencia de Brasil en el estado del mapa. M onografia, Universidad de B rasil, M rasil.

Rosas, H., Trevera, A., \& Rosas, M. (Enero.junio de 2009). La estructura burocrática y su flexibilidad para la innovación en los modelos de M ax W eber y Robert Merton. Revista Internacional La nueva Gestión Organizacional, 4(8), 98-111.
Santa Cruz, A. (1997). Comparando sistemas burocráticos: los casos de estados U nidos, Japón y M éxico. Espiral, V II(008), 93-110.

Torres, Z. (2002). Teoría general de la administración. M éxico: Editorial Patria.

Vásquez, R. (diciembre de 2006). Weber y su concepción de la democracia posible. Andamios, III(5), 213236.

Vélez, A. (2007). Los clásicos de la gerencia. Bogotá, Colombia: Editorial Universidad del Rosario.

Von Sprecher, R. (2005). Teorías Sociológicas: Introducción a los clásicos (Tercera ed.). Córdova: Editorial Brujas.

Zabludovsky, G. (2007). Sociología y cambio conceptual. M éxico: Siqlo XXI editores. 